\title{
Varicose pericardial vein: An unusual cause of right paracardiac opacity
}

Daniel Pop, MD, ${ }^{a}$ Nicolas Venissac, MD, ${ }^{a}$ Francesco Leo, MD, ${ }^{a}$ Dorothé Ducreux, MD, ${ }^{\mathrm{b}}$ Bernard Padovani, MD, ${ }^{\mathrm{b}}$ and Jérôme Mouroux, MD, ${ }^{a}$ Nice, France

$\mathrm{I}$

n case of portal hypertension, mediastinal veins can be varicose, and they might be interpreted on chest radiography or scanning as mediastinal or pulmonary masses. ${ }^{1}$ When no portal hypertension is present, the obstruction of the inferior vena cava might cause the presence of a dilated azygos-hemiazygos system $^{2}$ or, more rarely, a left varicose pericardiophrenic vein. $^{3}$

We report the first case of varix of the right pericardiophrenic vein without portal hypertension explored by means of videoassisted thoracoscopy because it was misinterpreted as a pleuropericardial cyst.

\section{Clinical Summary}

A right mass in the right cardiophrenic angle was discovered on chest radiography in a 60-year-old man after an episode of acute bronchitis. He stopped smoking in 1998 when his ischemic cardiac disease was discovered and treated with angioplasty and interventricular artery stenting. In 2002, a needle biopsy showed postalcoholic micronodular cirrhosis.

Two months later, respiratory symptoms were solved, but the radiologic image was unmodified. No anomaly was evident at clinical examination. No sign of portal hypertension was present. At this time, hematology showed no abnormality but a moderately increased level of $\gamma$-glutamyl transpeptidase (251 U/L). The results of electrocardiography were normal.

Chest scans showed 2 contiguous round lesions in the right cardiophrenic angle that were hypodense with regular borders and probably interconnected in their lower part (Figure 1). The largest nodule was the posterior one, and it measured $23 \mathrm{~mm}$ in diameter. Contrast injection showed no enhancement in both. Mild hepatomegaly was present.

We decided to perform a right video-assisted thoracoscopy for the clinical suspicion of a pleuropericardial cyst. At exploration, on the pericardium, a varicose and serpiginous network from the pericardiophrenic vein was found, extending from the diaphragm

\footnotetext{
From the Thoracic Surgery Department ${ }^{\mathrm{a}}$ and the Radiology Department, ${ }^{\mathrm{b}}$ Pasteur Hospital, Nice, France.

Received for publication May 6, 2004; accepted for publication May 24, 2004.

Address for reprints: Daniel Pop, MD, Thoracic Surgery Department, Pasteur Hospital-Building H, 30 Avenue de la Voie Romaine, 06002 Nice, France (E-mail: danielpopch@yahoo.com).

J Thorac Cardiovasc Surg 2005;129:448-9

$0022-5223 / \$ 30.00$

Copyright (C) 2005 by The American Association for Thoracic Surgery doi:10.1016/j.jtcvs.2004.05.027
}

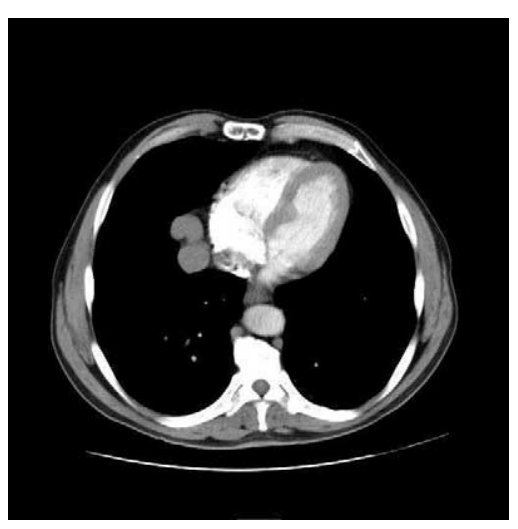

Figure 1. CT scan showing the bilobate mass.

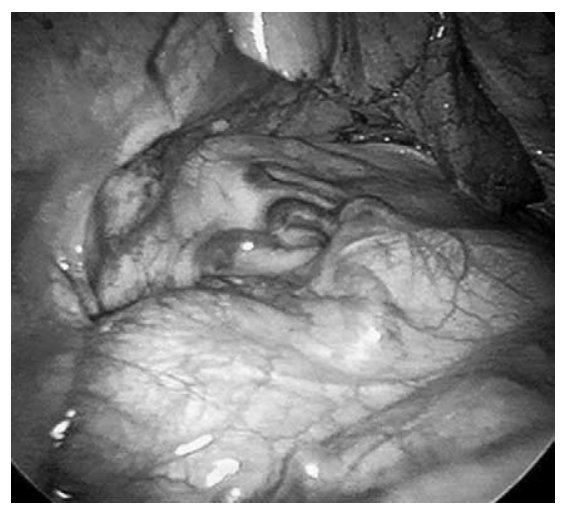

Figure 2. Videothoracoscopic view of the varicose pericardial vein.

to the upper paracaval region with a maximum diameter of approximately $1 \mathrm{~cm}$ (Figure 2).

The postoperative period was uneventful, and the patient was discharged 2 days after the operation.

An abdominal echocardiographic Doppler examination was performed 1 month later. It showed a membranous obstruction of the inferior vena cava $18 \mathrm{~mm}$ below the diaphragm in its retrohepatic portion, and only the right suprahepatic vein was visualized.

A course of simple surveillance was decided on in the absence of other abnormalities.

\section{Discussion}

The varix of the pericardiophrenic vein might represent a diagnostic pitfall because it can be erroneously interpreted as a pulmonary or mediastinal mass. 
The absence of contrast enhancement and hypodensity on computed tomographic scanning usually suggests the diagnosis of cystic lesions. Opacification of the thoracic collateral veins can be very difficult to obtain, and it depends on the amount of contrast material, the injection rate, and the timing of the administration. ${ }^{4}$

In the present case the site and density of the mass were consistent with the diagnosis of a pleuropericardial cyst.

The possibility of a mediastinal varix was not considered for the absence of other varicose abnormalities and the absence of clinically evident portal hypertension. The possibility of a membranous obstruction of the inferior vena cava was considered after surgical exploration and confirmed by means of echocardiographic Doppler examination.

The site of this rare abnormality was atypical. Of the 4 cases of paracardiac mass caused by mediastinal varices reported by Chung and colleagues, ${ }^{3}$ all were on the left side, and the pattern of drainage was from the hepatic veins through the left inferior phrenic vein to the left pericardiophrenic vein.

In the presented case, on the basis of surgical exploration, it was reasonable to assume that the drainage was from the right inferior phrenic vein through the right pericardiophrenic vein into the right thoracic vein. ${ }^{5}$
This observation suggests that isolated varicose abnormality of the pericardiophrenic vein should be considered in the differential diagnosis of mediastinal plurilobate masses. In this case a different timing in image uptake after contrast injection could support such a diagnosis and justify magnetic resonance, venocavography, or both, to avoid invasive diagnostic procedures such as videoassisted thoracoscopy.

\section{References}

1. Millward SF, Ramsewak W, Joseph G, Jones B, Zylak CJ. Pericardial varices demonstrated by computed tomography. J Comput Assist Tomogr. 1985;9:1106-7.

2. Podbielski FJ, Sam AD, Halldorson AO, Iasha-Sznajder J, Vigneswaran WT. Giant azygos vein varix. Ann Thorac Surg. 1997;63:1167-9.

3. Chung JW, Im JG, Park JH, Han JK, Choi CG, Han MC. Left paracardiac mass caused by dilated pericardiacophrenic vein: report of four cases. AJR Am J Roentgenol. 1993;160:25-8.

4. Trigaux JP, vanBeers B. Thoracic collateral venous channels: normal and pathologic CT findings. J Comput Assist Tomogr. 1990;14:769-73.

5. Lawler LP, Fishman EK. Pericardial varices: depiction on three-dimensional computed tomographic angiography. AJR Am J Roentgenol. 2001;177:202-4.

\title{
Foreign-body excretion through the bronchial stump after extrapleural pneumonectomy
}

\author{
Kenichi Okubo, MD, and Yasunori Kurahashi, MD, Gifu, Japan
}

$\mathrm{F}$ oreign-body excretion is a bioresponse of the human body. Bronchial foreign bodies commonly occur through aspiration or inhalation. We present a rare case of the excretion of a foreign body through the bronchial stump 19 months after pneumonectomy.

\section{Clinical Summary}

A 52-year-old man had a high fever and chest discomfort. He underwent a left extrapleural pneumonectomy for malignant pleural mesothelioma 19 months earlier. He received postoperative chemotherapy, which consisted of 4 cycles of cisplatin, doxorubicin, and cyclophosphamide, and sequential radiation therapy for

From General Thoracic Surgery, Gifu National Hospital, Gifu, Japan

Received for publication April 11, 2004; revisions received May 7, 2004; accepted for publication May 24, 2004.

Address for reprints: Kenichi Okubo, MD, General Thoracic Surgery, Gifu National Hospital, 5-1-1 Hinohigashi, Gifu 500-8718, Japan (E-mail: okubo@gifu.hosp.go.jp).

J Thorac Cardiovasc Surg 2005;129:449-50

$0022-5223 / \$ 30.00$

Copyright $\odot 2005$ by The American Association for Thoracic Surgery

doi:10.1016/j.jtcvs.2004.05.028 the entire hemithorax of $56 \mathrm{~Gy}$ in total. ${ }^{1,2}$ Blood count showed luekocytosis, and chemistry showed an increased C-reactive protein level. Chest radiography showed no abnormal lesions except for left-side opacity after pneumonectomy. Computed tomography of the chest and the abdomen showed no evidence of recurrence of malignant pleural mesothelioma. Culture of thoracentesis fluid showed no growth of microorganisms. Bronchoscopic examination revealed a foreign body, a whitish cottony material, at the left main bronchial stump (Figure 1). Endoscopic extraction with forceps identified a hemostat of oxidized cellulose (Figure 2). After the extraction, a blue suture was translucently identified in the mucosa of the bronchial stump. Bronchopleural fistula was not seen during or after the extraction. Culture of the material revealed Haemophilus species. After the removal of the infected foreign body, the patient recovered quickly and has been doing well for 3 years.

The bronchial stump at the left extrapleural pneumonectomy was hand sutured with interrupted polypropylene sutures (3-0 Prolene; Ethicon Inc, Somerville, NJ) and reinforced with a pedicled intercostal muscle by using the same polypropylene sutures for bronchus. On the next day, the patient underwent a re-exploration of the thorax as a result of the excessive blood loss. After hemostasis was obtained, cotton-type oxidized cellulose (Oxycel; Sankyo Co, Tokyo, Japan) was inserted into the mediastinum as a hemostat. Bronchoscopic examination 4 weeks after the pneumo- 